JOURNAL

of Health Inequalities

\title{
The "Keep Fit!" programme for building health-competence in children and adolescents in Poland regarding their diet and physical activity - study design
}

\author{
Paulina Wojtyła-Buciora ${ }^{1,2}$, Tomasz Bołdowski ${ }^{3}$, Cezary Wojtyła ${ }^{4}$, Wiola Żukiewicz-Sobczak ${ }^{5}$, \\ Krzysztof Wojtyła ${ }^{2}$, Zuzanna Chęcińska-Maciejewska' ${ }^{1}$ Andrzej Wojtyła² ${ }^{2}$ Hanna Krauss ${ }^{1}$ \\ 'Department of Physiology, University of Medical Sciences, Poznan, Poland \\ ${ }^{2}$ Higher Vocational State School, Kalisz, Poland \\ ${ }^{3}$ Department of Emergency Medicine, Poznan University of Medical Sciences, Poznan, Poland \\ ${ }^{4}$ Centre of Postgraduate Medical Education, I Department of Obstetrics and Gynecology, Warsaw, Poland \\ ${ }^{5}$ Pope John Paul II State School of Higher Education in Biala Podlaska, Poland
}

\begin{abstract}
Introduction: The "Keep Fit!" programme is an initiative for promoting healthy lifestyles in schoolchildren, which uses a two-pronged approach of focusing on a balanced diet combined with regular physical activity. Hitherto, nine editions of the programme have taken place, involving more than seven million pupils attending over 8800 schools. Due to its scope and coverage being so wide, the "Keep Fit!" programme was recognised as being the largest educational programme in the European Union. The aim of the present study was to investigate the health behaviours of pupils and students in Poland, with focus on their eating habits, physical activity, self-assessed weight, psychoactive substance use, and the impact that taking part in the "Keep Fit!" programme had on changing their lifestyle.

Material and methods: The study involved cross-sectional surveys in Poland conducted in 2009 among randomly selected samples of junior high-school pupils (ages 13-16), and in 2011 of pupils attending junior high school, high school (ages 17-19), as well as university students aged 25 and younger. The questionnaire was devised by the Chief Sanitary Inspectorate (GIS). Data was analysed from correctly completed questionnaires among 9,360 and 11,863 eligible respondents in 2009 and 2011, respectively. Results: Among eligible survey respondents, 53\% (4970) in 2009 and 14\% (1674) took part in the "Keep Fit!" programme. Both in 2009 and 2011 the "Keep Fit!" programme has made a significant and beneficial impact in terms of eating habits and physical activity among programme participants.

Conclusions: The "Keep Fit!" programme should be continued so as to prevent overweight, obesity, and other chronic non-communicable diseases from occurring in schoolchildren.
\end{abstract}

KEY WORDS: diet, physical activity, health behaviour, children and adolescents, “Keep Fit!" programme, Poland.

\section{KEY FINDINGS}

1. The results suggest that the national "Keep Fit!" programme had beneficial effects on shaping attitudes and behaviour regarding proper nutrition and maintaining a physically active lifestyle.

2. "Keep Fit!" participants showed an increased health awareness reflecting the effectiveness of the programme and the need for its continuation in subsequent years of school education.

ADDRESS FOR CORRESPONDENCE: Paulina Wojtyła-Buciora, Department of Physiology, University of Medical Sciences, 6 Święcickiego Street, 60-781 Poznan, Poland, e-mail: paulinawojtyla@gmail.com 


\section{INTRODUCTION}

Childhood obesity constitutes one of the most serious public health problems of the $21^{\text {st }}$ century. A global study has reported a $47 \%$ increase in rates of child obesity between 1980 and 2013 [1]. The International Association for the Study of Obesity estimates that around 200 million schoolchildren throughout the world suffer from overweight and 40-50 million from obesity. If current trends continue, it is also estimated that by 2030 , $38 \%$ of the world's adult population will be overweight and $20 \%$ will be obese [2]. At present, overweight and obesity constitute the fifth leading global factor that increases the risk of premature death, being responsible annually for 2.8 million deaths [3]. Premature mortality for obese persons is mainly due to cardiovascular disease: ischaemic heart disease, hypertension, and heart failure [4-6]. Many epidemiological studies have also demonstrated that obesity is linked to increased risks of cancer, which includes the colon, breast, uterus, liver, kidneys, oesophagus, stomach, gallbladder, and pancreas [7].

One of the main causes of obesity is the lack of, or insufficient levels of physical activity. Only $30 \%$ of adolescents perform enough physical exercise to ensure normal physical, mental, and emotional development [8]. During the last 20 years most developed countries of the world have witnessed a growing trend of leading a sedentary lifestyle [9]. A "Department of Health and Social Welfare" report from the United States showed that school-age children spend an average of 7 hours and 11 minutes per day either watching TV or being on a computer [10]. Undoubtedly, this outcome has been brought about by modern technological advances that had caused changes to our lifestyle, as well as a lack of awareness that undertaking physical activity is vital for normal human development. Such a situation poses a threat to health, disrupts normal child development, and above all else, results in obesity occurring during later years of life, thereby increasing the risk of acquiring $21^{\text {st }}$-century lifestyle diseases.

There is consequently a need to design and run educational programmes in order to promote healthy lifestyle behaviour for children and adolescents regarding healthy eating and engaging in regular physical activity. To address this in Poland, the "Keep Fit!" initiative was launched for promoting a healthy lifestyle, especially in junior high-school pupils, which focused on eating a balanced diet combined with regular physical activity. This programme was run in accordance with WHO recommendations arising from a global strategy on diet, physical activity, and health, which were outlined in both the Green and White Papers of the European Commission (EC) for encouraging Member States (MS) to increase their efforts to promote healthy diets and physical activity, these being recognised as effective methods for preventing overweight, obesity, and other chronic diseases.

\section{THE NATIONAL “KEEP FIT!” PROGRAMME AS A PROJECT METHOD}

The "Keep Fit!" programme is an initiative for furthering a healthy lifestyle in schoolchildren through adopting a two-way approach of promoting a balanced diet combined with regular physical activity. This National Educational Programme is organised and managed jointly by the Chief Sanitary Inspectorate (GIS) and the Polish Federation of Food Industry Employers' Association (PFFI) as part of the WHO strategy on diet, physical activity, and health. Partners of the programme are the Polish Agricultural Market Agency, the Lublin Institute of Rural Medicine (i.e. The Witold Chodzki Memorial Institute), the Institute of Food and Nutrition, the Faculty of Human Nutrition and Consumers at Warsaw University of Life Sciences, and the Federation of Consumers. Honorary Patrons are the Minister of Education, the Minister of Health, the Minister of Sport and Tourism, and the Minister of Agriculture and Rural Development.

The programme is open to all public and private schools at primary (last year) and junior high-school levels. Those schools wanting to take part in the programme are asked to contact the appropriate District Sanitary and Epidemiological Station. The local coordinators of the programme are employees of the Division of Health Education and Health Promotion at the State Sanitary Inspectorate, who provide active support to the school for its implementation. Such schools receive a free set of modern teaching materials designed for teachers, students, and parents, which guarantee rapid access to the necessary expertise required for the programme. The running of the programme is integrated into a normal school curriculum in the form of several additional items that are carried out at different times. The teaching materials consists of: a guide for teachers, a student's brochure, a leaflet for parents, and a "Platter of Health" poster designed by the Health Council on Diet, Physical Activity, and Health from the Polish Ministry of Health. Educational materials were prepared in collaboration with leading institutions and scientific centres dealing with food, nutrition, and health i.e. the Institute of Food and Nutrition, the Department of School Medicine at the Mother and Child Institute, and the Polish Society for the Study of Obesity. The programme also included parents, as they bear a decisive influence on the behaviour patterns of their children; by following their example, this is the best way for children to develop pro-healthy attitudes regarding nutrition and physical activity.

Of the nine editions of the programme undertaken so far, more than seven million pupils attending over 8800 schools have been involved. It should be stressed that such was the scope and large number of pupils and schools that were covered, that the EU recognised it to be the largest educational programme in the EU. Furthermore, upon assessing the programme, the European Platform for Action on Diet, Physical Activity, and 
Health held it an exemplary model, and thereby recommended it to be used for other EU countries.

"Keep Fit!" programme is aimed at forming and then nurturing the interests and capabilities of students to lead a healthy lifestyle. It serves to promote physical activity, teaches eating a normal and varied balanced diet to children and adolescents, where particular emphasis is placed on taking responsibility for one's health whilst incorporating the principle of making free and informed choices. Such a programme design allows great freedom to choose how it is run, which lets pupils seek out and use their own ideas for pro-health outcomes, thus making an undoubted impact on its effectiveness. The project is interdisciplinary, and it treats the issue of a healthy lifestyle (holistically), incorporating training of specific skills, as well as forming attitudes and developing interest in pro-health matters. The efforts put in by pupils were coupled with their expectations together with engaging with the school environment and local community to exploit the latest knowledge available in achieving the programme's ends. The programme consists of four stages: preparation (i.e. developing the theme and purpose of the project), planning (presenting a schedule and establishing performance criteria), implementation, and then dissemination of outcomes. The most important goal of the project is to develop pupil skills in terms of: accepting responsibility, creative thinking, independent learning, planning and organising the work, gathering and selecting information, as well as the skills required for group collaboration, problem solving, decision making, communication, evaluating their own work, and presenting the results [11].

After completing each edition of the programme, the school coordinators prepare a report describing the programme's performance, which is then relayed to the appropriate district sanitary-epidemiological station. In Poland, the network of such stations consists of 16 offices at the provincial level and 318 at the local district level. At the national level, the programme organisers are obliged to provide a summary and evaluation of how the programme has been running, upon which suitable changes can be proposed for subsequent rollouts. Up till now over 24,000 original projects have been developed; a small sample of their slogans being: "Keep Fit for the Family", "A recipe for a healthy life", "Lose weight - but how?", "Health is vital", "Time for health" "Keep Fit - live healthily", and "For a healthy body a healthy mind".

\section{PROGRAMME MONITORING}

The first monitoring of the National Educational Programme "Keep Fit!" was carried out in 2009 on junior high-school pupils and their parents. Another evaluation was undertaken in 2011; this time for pupils of junior high school and high school, and university students. Their ultimate aims were to investigate health behaviours of survey respondents regarding eating habits, undertaking physical activity, self-assessment of weight, psychoactive substance use, and effects of taking part in the "Keep Fit!" programme on changing their habits, including comparison between "Keep Fit!" participants and non-participants.

\section{MATERIAL AND METHODS}

The surveys conducted in 2009 and 2011, as described above, adopted four selection criteria for pupils as follows: region (16 provinces), place of residence (divided into rural and urban), classroom grade (first, second, and third), and gender. A two-stage random sampling was used: the first stratified sampling at the school level and the second at the class level.

Schools were picked through using Statistica and SPSS procedures. Because the subject groups were expanded in 2011, the sampling was limited to four types of schools (junior high school, high school, specialised secondary school, and technical college). The sampling was clustered (at school and class level), with i.e. pupils who were randomly selected for participation completed the questionnaire anonymously. It was assumed that each class was composed of 30 students. This few hundred or so respondents translated into much greater numbers when multiplied by the number of randomly selected schools, and thus gave the opportunity for greater differentiation by location for junior high schools within individual provinces. The sampling was done from a database of schools and students held at the Ministry of National Education on 30 September 2008. The sample consisted of 569 schools from 379 districts.

The study had previously received Bioethical Committee approval and was conducted after consulting with the relevant education authorities at central, district, and provincial levels. After obtaining their agreement, the study was performed during school time and was both voluntary and anonymous. The interviewers came from health education units of the State Sanitary Inspection previously trained by staff from the Chief Sanitary Inspectorate in its system cascade of operation. The paper responses were then entered into a central database by means of an integrated system of data collection and entry.

\section{SURVEY QUESTIONNAIRE DESIGN}

At both assessment times data was collected using a questionnaire devised by the Chief Sanitary Inspectorate, based on a tool that had been used in the GSHS study before (Global School-base Student Health Survey). The questionnaire was divided into modules covering the following areas: physical activity, eating habits, physique, substance abuse, health self-esteem, and wellbeing of young people. The modules grouped into specific questions were preceded by questions on age, gender, classroom grade attended, family status (i.e. a full or broken family), number of siblings, place of residence, and 
travelling to and from school. Finally, survey respondents were asked to indicate if they have participated in "Keep Fit!" programme/activities to enable comparison of other outcomes across programme participants and non-participants. The 2009 survey was addressed not only to junior high-school students, but also to their parents so as to obtain more reliable data for particular health behaviours, i.e. by checking the responses of children with those of their parents. The parents' questionnaires were supplied in sealed envelopes to pupils and then taken home to be completed by the parents. On an appointed day they were returned to the school teacher. In 2011, however, the parents were not surveyed because of the low agreement between pupil and parent responses that had been found in 2009 .

Pupil respondents from 2011 were surveyed by electronic means via an internet site (the Institute of Agricultural Medicine website), in contrast to junior high-school and high-school pupils. The internet access was granted to students throughout Poland. An information campaign was carried out in parallel on how to fill in the questionnaire. The sample subjects were then randomised according to gender and age by means of another randomisation using the aspect ratio for the population of Polish universities (GUS "Universities and their finances in 2009"). The study was limited to students aged up to 25 years because for older groups the "Keep Fit!" programme had not been initiated at the time of their education. Because the data were gathered according to the place of residence and type of school attended, a specific adjustment was made to the composition of the various subject groups in the sample.

It was found that the way in which the study procedure itself relied on students completing the web-site questionnaire could have introduced systematic errors in that subjects were being informed on how and by what time they had to complete the survey. To correct for this, any excess subjects found per group were either again randomised or those that committed errors or repetitions in filling out the forms were eliminated from the study. In such ways structural adjustments were made. In 2011, an assessment of physical activity was performed according to a shortened form of the IPAQ questionnaire (International Physical Activity Questionnaire).

\section{STATISTICAL ANALYSIS}

The data collected into the database were then subject to statistical analyses using STATISTICA environment 12 software. The associations between discrete-scale variables in multi-field tables were assessed by the $\chi^{2}$ test. For those variables that were on a continuous or ordinal scale, the Kruskal-Wallis test was used (i.e. a non-parametric analysis of variance); a $P$ level of above 0.05 was taken as being insignificant.

\section{STUDY POPULATION CHARACTERISTICS/ PROFILE}

As mentioned previously, questionnaires issued in 2009 were targeted to a randomly selected group of junior high-school pupils, consisting of 12,005 subjects, and a corresponding number of parents. Those qualifying for statistical analysis were 9360 (78\%) pupil respondents who correctly completed questionnaires and 6951 (58\%) parents. Of these, 4970 subject pupils (i.e. $53 \%$ of eligible respondents) took part in the "Keep Fit!" programme. When allowing for regional variations, most participating pupils came from the provinces of Lesser Poland (Małopolska), Mazovia (Mazowsze), Lower Silesia (Dolny Ślask), Greater Poland (Wielkopolska), Lublin and Silesia (Ślask) (Fig. 1). Subjects in total consisted of 2684 (54\%) girls and $2286(46 \%)$ boys, whilst those living in urban and rural areas were 3131 (63\%) and 1839 (37\%), respectively.

The 2011 arm of the "Keep Fit!" monitoring study consisted, as mentioned previously, of randomly selected pupils coming from junior high school and high school ( $n=13,537)$. For the purposes of being qualified for statistical analysis, 11,863 (88\%) had correctly filled in questionnaires, of whom 1674 (14\%) respondents took part in the "Keep Fit!" programme; of these most lived in the provinces of: Pomerania (Pomorze), Lublin, Greater Poland (Wielkopolska), Podlasia (Podlaska), and Mazowia (Mazowsze) (Fig. 2). Of those participating, 773 (46\%) were girls and 901 (54\%) were boys; 704 (42\%) lived in urban areas and $970(58 \%)$ came from rural areas. Furthermore, the randomised subjects were divided into three age groups: $12-15$ years, 16-18 years, and students aged over 18 years. Those participating in the "Keep Fit!" programme numbered 735 (44\%) pupil respondents aged 12-15 years, $730(44 \%)$ pupil respondents aged 16-18 years, and 209 (12\%) students over 18 years of age.

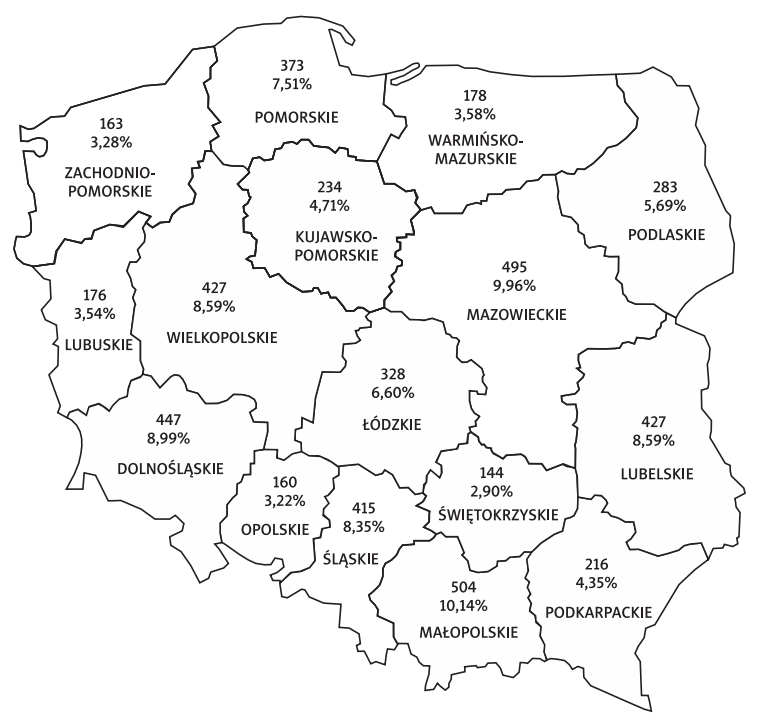

FIG. 1. The regional distribution of 2009 survey respondents who reported participating in the "Keep Fit!" programme 


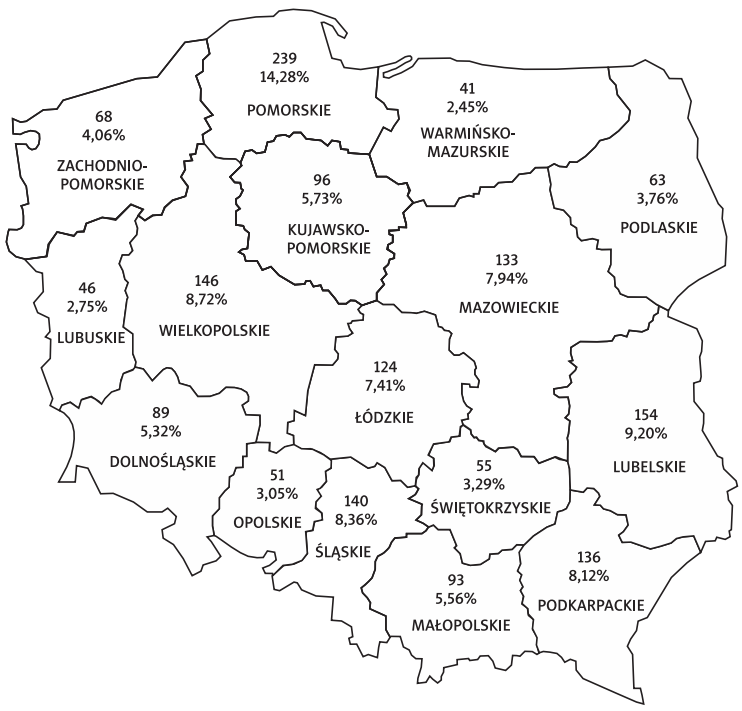

FIG. 2. The regional distribution of 2011 survey respondents who reported participating in the "Keep Fit!" programme

\section{RESULTS}

The assessments conducted in 2009 and 2011 demonstrated a significantly favourable impact of the "Keep Fit!" programme under the auspices of the National Educational Programme regarding eating habits and physical activity undertaken by respondents [12]. Beneficial areas have been identified, where survey respondents had opted for adopting the following:

- Regularly eating breakfast and other daytime meals.

- Less frequently eating high-calorie meals, especially fast foods and sweets.

- Lowered rates of unhealthy eating habits such as overeating or snacking between main meals.

- Taking part in physical exercises at school for longer hours.

- An overall high level of daily physical activity, especially for the youngest programme participants living in rural areas and teenage boys - these being much more active than girls.

- A positive attitude/behaviour in youngsters for engaging in physical activity during their leisure time.

- More frequently choosing an active way of travelling to and from school (e.g. walking or cycling), and in using sports facilities.

- A normal body mass index (BMI) being commonly found, (i.e. an average BMI of 20.74), where lowered BMIs were observed in both girls and boys living in rural areas and small towns (of less than 100,000 inhabitants).

- Lower rates of overweight and obesity.

- More appropriate self-assessed body weight, a higher level of body self-acceptance, and greater satisfaction with appearance.

- Rare attempts at slimming.
The "Keep Fit!" surveys of 2009 and 2011 did not, however, reveal any effect that the programme may have had on the widespread habits of smoking cigarettes, drinking alcohol, and drug abuse for those participating.

\section{CONCLUSIONS}

1. Since 2006, the "Keep Fit!" programme was found to have a beneficial effect on diet, physical activity, and health, where nutrition and engaging in physical activity were all at favourable/adequate levels for participants.

2. The programme should be continued, using its current methods.

3. An evaluation of the programme is indicated for 2017 to summarise the ten years of its being run.

4. An epidemiological study is required to compare nutritional behaviour and physical activity between programme participants and non-participants by using the international Food Frequency Questionnaire (FFQ) and the full version of IPAQ.

5. Because the "Keep Fit!" programme is focused on diet, physical activity, and health, an educational and health promotion programme should be run in parallel and targeted at reducing psychoactive substance abuse in adolescents.

\section{DISCLOSURE}

Authors report no conflict of interest.

\section{References}

1. Ng M, Fleming T, Robinson M, et al. Global, regional and national prevalence of overweight and obesity in children and adults during 1980-2013: a systematic analysis for the Global Burden of Disease Study 2013. Lancet 2014; 384: 766-781.

2. Smith KB, Smith MS. Obesity Statistics. Prim Care 2016; 43: 121-135.

3. Global status report on noncommunicable disease 2010. Geneva: World Health Organization 2010. Available from: http://www. who.int/nmh/publications/ncd_report_full_en.pdf (accessed 29 November 2016).

4. Britton KA, Massaro JM, Myrabiti JM, et al. Body fat distribution, oncident cardiovascular disease, cancer and all-cause mortality. J Am Coll Cardiol 2013; 62: 921-925.

5. Twig G, Yaniv G, Levine H, et al. Body-Mass Index in 2.3 Million Adolescents and Cardiovascular Death in Adulthood. N Engl J Med 2016; 374: 2430-2440.

6. Antwi F, Fazylova N, Garcon MC, et al. The effectiveness of web-based programs on the reduction of childchood obesity in school-aged children: A systematic review. JBI Libr Syst Rev 2012; 10 (42 Suppl): 1-14.

7. Tahergorabi Z, Khazaei M, Moodi M, Chamani E. From obesity to cancer: a review on proposed mechanisms. Cell Biochem Funct 2016; 34: 533-545.

8. Kantomaa MT, Tammelin TH, Demakakos P, et al. Physical activity, emotional and behavioural problems, maternal educa- 
tion and self-reported educational performance of adolescents. Health Educ Res 2010; 25: 368-379.

9. Wojtyla-Buciora P, Stawinska-Witoszynska B, Wojtyla K, et al. Assessing physical activity and sedentary lifestyle behaviours for children and adolescents living in a district of Poland. What are the key determinants for improving health? Ann Agric Environ Med 2014; 21: 606-612.

10. Morbidity and Mortality Weekly Report (MMWR). School Health Guidelines to Promote Healthy Eating and Physical Activity Recommendations and Reports 2011; September 16 2011/60(RR05): 1-71. Available from: http://www.cdc.gov/MMWR/preview/mm wrhtml/rr6005al.htm (accessed 29 November 2016).

11. Trzymaj Formę. Available from: http://www.trzymajforme.pl/ strona-glowna-11 (accessed 29 November 2016).

12. Wojtyła-Buciora P, Bołdowski T, Żukiewicz-Sobczak W, et al. The impact of the "Keep Fit!" national programme in Poland on diet, physical activity and health during 2006-2011 in children and adolescents. J Health Inequal 2016; 2: 67-76.

\section{AUTHORS' CONTRIBUTIONS}

PWB, WŻS, AW prepared the research concept and design of the publication. TB, WZZS, ZChM collected data. PWB, TB, KW, ZChM analysed data. PWB and CW wrote the article. CW and AW critically reviewed the publication. HK finally approved the publication. 